\title{
ROLE OF L-ORNITHINE IN MITIGATION OF SALT STRESS IN ALLIUM CEPA L.
}

\author{
Kürşat ÇavuşoĞLu ${ }^{*}$ and Dilek ÇavuşoĞlu ${ }^{1}$ \\ Süleyman Demirel University, Faculty of Arts and Science, \\ Department of Biology, 32260 Isparta / Turkey
}

Keywords: Cytogenetical parameters, Onion, Ornithine, Physiological parameters, Salt stress

\begin{abstract}
Effects of L-ornithine $(150 \mathrm{mg} / \mathrm{l})$ on the germination, seedling growth, mitotic index, chromosome aberrations and micronucleus frequency of Allium cepa L. bulbs germinated at $0.125 \mathrm{M}$ salinity were studied. The radicle number of the group III bulbs germinated in the medium with ornithine alone as compared to ones of the group I (control) bulbs which germinated in distilled water medium. But, their germination percentage, radicle length and fresh weight were statistically the same as ones of the group I bulbs. Besides, the micronucleus frequency and chromosomal abnormalities in the root-tip meristematic cells of the group III bulbs showed increased germination compared to ones of the group I bulbs. However, their mitotic index statistically showed the same value as the group I bulbs. Salt stress significantly inhibited the germination and seedling growth of $A$. cepa bulbs. Moreover, it reduced the mitotic index in the root-meristem cells of the bulbs and fairly increased the number of chromosome aberrations and micronucleus frequency. On the other hand, the inhibitive effect of salt on the germination, seedling growth, mitotic index and micronucleus frequency was dramatically alleviated in varying degrees by ornithine application. But, it was ineffective in reducing the detrimental effect of salinity on the chromosome aberrations. The germination percentage, radicle lenght, radicle number, fresh weight, mitotic index, micronucleus frequency and chromosomal aberrations of the group II seedlings grown in $0.125 \mathrm{M}$ salinity were $27 \%, 13.5 \mathrm{~mm}, 18.4,7.1 \mathrm{~g}, 5.5,18.3$ and $60.8 \%$, respectively while these values became $68 \%, 16.4 \mathrm{~mm}, 16.4,10.5 \mathrm{~g}, 15.6,7.6$ and $74.8 \%$ in the group IV seedlings treated with L-ornithine.
\end{abstract}

\section{Introduction}

Salinity is an important bordering environmental factor in crop production. Under salt stress, plants need to get over water stress, exposed by the low external water potential, and with ion toxicity, due to accumulation inside the plant. The plants must also cope with ion toxicity accumulated when exposed to salinity stress. As plants are sessile they must cope with changing environmental conditions by adapting to stress situations via various physiological and molecular processes. High salt concentration in soil may lead to three main types of stress, namely osmotic, oxidative and ionic stress (Shrivastava and Kumar 2015). Salt stress has various effects on plant physiological processes such as increased respiration rate and ion toxicity, mineral distribution, changes in plant growth, membrane permeability, membrane instability due to calcium displacement by sodium and reduced photosynthesis (Demidchik et al. 2018).

Ornithine, a non-essential amino acid, serves as the precursor for biosynthesis of polyamines, with the first and rate-limiting being catalyzed by ornithine decarboxylase. It is not a constituent of proteins, but is important in the regulation of nutritional state as a precursor of aliphatic polyamines. It can act in many biological processes including fruit ripening and plant protection from osmotic stress. In other words, it is used as the precursor of many metabolic pathways associated with stress resistance. L-ornithine is an important chemical used in medicine (wound healing, liver disease treatment), microorganism fermatiation, pharmaceutical and food industry (Mattoo and Handa 2008, Schneider et al. 2012).

*Author for correspondence: <kursatcavusoglu@sdu.edu.tr>. ${ }^{1}$ Isparta University of Applied Sciences, Atabey Vocational High School, Department of Plant and Animal Production, 32670 Isparta/Turkey. 
Allium cepa test one of the most frequently used plant bioassays has been used to evaluate the mutagenic effects in the root tips of onions. Its substantial value is supported by the fact that effects of mutagenic action of many compounds on the Allium test cells and mammalian cells are very similar. This test has been validated in internetional collaborative studies under the United Nations Environmental Program (UNEP), World Healt Organization (WHO) and US Environmental Protestion Agency (USEPA) as an effective test for environmental and genetic monitoring (Gajalakshmi and Ruban 2014). The present study was designed to examine the influences of L-ornithine in reducing the detrimental effects of salt stress on the germination, seedling growth, mitotic activity, micronucleus frequency and chromosomal aberrations of Allium cepa $\mathrm{L}$.

\section{Materials and Methods}

Allium cepa $\mathrm{L}$. bulbs were used as experimental material where ornithine doses $(1,5,10,20$, $\left.30,40,50,100,150,200,250,300,350,400,450,500,600,700,800,900,1000 \mathrm{mg} / \mathrm{L}^{-1}\right)$ and salt concentrations $(0.05,0.10,0.125,0.15,0.175,0.20,0.25,0.30,0.40,0.50 \mathrm{M})$ were applied in a preliminary investigation. The salt concentration preventing the germination of onion bulbs was determined as $0.125 \mathrm{M}$. The best promoting germination and seedling growth against the inhibitory effect of $0.125 \mathrm{M}$ salinity was established as $150 \mathrm{mg} / \mathrm{L}^{-1}$ the ornithine concentration. Thus, the mentioned concentrations were used in this work. The present study was carried out in Plant Physiology and Cytogenetic Laboratories of Biology Department in Faculty of Art and Science, Süleyman Demirel University

Germination experiments were carried out at a constant temperature $\left(20^{\circ} \mathrm{C}\right)$, in the dark in an incubator. Healthy and approximately equal-sized A. cepa bulbs were selected. Twenty bulbs from each treatment group were placed into the plastic containers. The bulbs were divided into four groups: Group I (control) was treated with distilled water for 7 consecutive days. Group II was treated with $0.125 \mathrm{M} \mathrm{NaCl}$ alone, for 7 consecutive days. Group III was treated with a $150 \mathrm{mg} / \mathrm{L}^{-1}$ dose of L-ornithine, for 7 consecutive days. Group IV was treated with a $150 \mathrm{mg} / \mathrm{L}^{-1}$ dose of Lornithine $+0.125 \mathrm{M} \mathrm{NaCl}$, for 7 consecutive days. Plastic containers were placed into an incubator for germination. It was assumed that the radicle should be $10 \mathrm{~mm}$ long for germination to take place. At the end of the 7 day, after determination of the final germination percentages, radicle numbers were also recorded, and radicle lengths of the seedlings were measured in $\mathrm{mm}$ and in addition, the fresh weights in $\mathrm{g} / \mathrm{seedling}$ were determined. All experiments were repeated 3 times.

After several days, root tips of germinated A. cepa were excised $(1-1.5 \mathrm{~cm}$ segment) for cytogenetic analysis. Then, they were pretreated with saturated para-dichlorobenzene for $4 \mathrm{hrs}$, fixed in solution of ethanol: acetic acid (3:1) overnight at room temperature and stored at $4^{\circ} \mathrm{C}$ in $70 \%$ ethanol until used. The root tips were hydrolysed in $5 \mathrm{~N} \mathrm{HCl}$ for $20 \mathrm{~min}$, stained with Feulgen for 1-1.5 hrs, smashed in a drop of $45 \%$ acetic acid and squashed. After $24 \mathrm{hrs,}$ microscopic slides were made permanent by mounting in balsame. The mitotic phases and mitotic aberrations were photographed (500X) with a digital camera (Olympus C-5060) after mounting on an Olympus CX41 microscope. Mitotic index, i.e. percentage of dividing cells scored was evaluated by analysing at least 9.000 cells per treatment (approx. 3.000 per slide). Statistical evaluation concerning all parameters was made by using SPSS program according to DMRT.

\section{Results and Discussion}

The germination percentage, radicle length and fresh weight of the group III bulbs germinated in the medium with L-ornithine were statistically the same as ones of the group I bulbs germinated in distilled water medium. But, their radicle numbers partly decreased according to ones of the 
group I seedlings (Table 1). So far no study has been conducted regarding the effects of Lornithine on the germination and seedling growth under normal conditions.

Table 1. Effect of L-ornithine on some growth parameters of Allium cepa $\mathbf{L}$.

\begin{tabular}{lcccc}
\hline \multirow{2}{*}{ Groups } & \multicolumn{4}{c}{ Growth parameters } \\
\cline { 2 - 5 } & $\begin{array}{c}\text { Germination } \\
(\%)\end{array}$ & $\begin{array}{c}\text { Radicle length } \\
(\mathrm{mm})\end{array}$ & $\begin{array}{c}\text { Radicle } \\
\text { number }\end{array}$ & $\begin{array}{c}\text { Fresh weight } \\
(\mathrm{g} / \mathrm{seedling})\end{array}$ \\
\hline Group I & $* 100 \pm 0.0^{\mathrm{c}}$ & $58.7 \pm 0.7^{\mathrm{c}}$ & $45.1 \pm 0.7^{\mathrm{d}}$ & $10.5 \pm 0.3^{\mathrm{b}}$ \\
Group II & $27 \pm 2.8^{\mathrm{a}}$ & $13.5 \pm 1.2^{\mathrm{a}}$ & $18.4 \pm 1.4^{\mathrm{b}}$ & $7.1 \pm 0.2^{\mathrm{a}}$ \\
Group III & $100 \pm 0.0^{\mathrm{c}}$ & $57.7 \pm 1.1^{\mathrm{c}}$ & $38.9 \pm 0.7^{\mathrm{c}}$ & $9.8 \pm 0.9^{\mathrm{b}}$ \\
Group IV & $68 \pm 2.8^{\mathrm{b}}$ & $16.4 \pm 0.6^{\mathrm{b}}$ & $16.4 \pm 0.6^{\mathrm{a}}$ & $10.5 \pm 0.3^{\mathrm{b}}$ \\
\hline
\end{tabular}

*The difference between values with the same letter in each column is not significant at the level $0.05( \pm \mathrm{SD})$. Group I (control) was treated with distilled water, Group II treated with $0.125 \mathrm{M} \mathrm{NaCl}$ alone, Group III treated with $150 \mathrm{mg} / \mathrm{L}^{-1}$ dose of L-ornithine, Group IV treated with $150 \mathrm{mg} / \mathrm{L}^{-1}$ dose of L-ornithine+0.125 M $\mathrm{NaCl}$.

Salt stress showed a restrictive effect on all examined growth parameters. For instance, the group I (control) bulbs displayed $100 \%$ germination on the 7 day while this value became $27 \%$ in the group II bulbs germinated in $0.125 \mathrm{M}$ salinity. In other words, salt prevented $73 \%$ the germination of A. cepa bulbs (Table 1). Salt stress can perform its preventive effect in many ways. It may interfere with seed germination by changing the water status of the seed so that water uptake is inhibited (Flowers and Colmer 2015). The present results showing the decrease in the fresh weight and water content of the seedlings in saline medium may be explained by the failure of the roots to receive sufficient water due to the high osmotic pressure of the medium. The inhibitory effect of salt on the radicle length and radicle number may result from reducing cell division, nucleic acid and protein synthesis (Roy et al. 2014).

L-ornithine application markedly mitigated the inhibitive effect of salt stress on the germination. The group IV bulbs treated with L-ornithine demonstrated $68 \%$ germination in the mentioned salt level (Fig. 1). L-ornithine also continued its success on the seedling growth parameters such as the radicle length and fresh weight. The radicle length and fresh weight of the group II seedlings grown in $0.125 \mathrm{M}$ salinity were $13.5 \mathrm{~mm}$ and $7.1 \mathrm{~g}$, respectively while these values were $16.4 \mathrm{~mm}$ and $10.5 \mathrm{~g}$ in the group IV seedlings treated with L-ornithine. But, this application was unsuccessful in alleviation of the inhibitive effect of salt stress on the radicle number of the seedlings (Table 1). That L-ornithine alleviates salt stress on the germination and seedling growth can be estimated from the decrease in the salt's osmotic effects. For example, at $0.125 \mathrm{M} \mathrm{NaCl}$ medium, L-ornithine application partly increased the fresh weights of the seedlings compared to the control indicating this probability (Table 1). Moreover, it reduced the preventive effect of salt on the germination and seedling growth by stimulating mitotic activity of the embryo (Table 2).

Data relating to effects of L-ornithine on the mitotic activity, micronucleus frequency and chromosomal aberrations in non-stress and salt stress conditions are not still available. Thus the present study was carried out to find whether L-ornithine is affecting these parameters in normal conditions or not. The data obtained in the present work indicated that the mitotic index in root tip meristems of the group III bulbs germinated in the medium with L-ornithine alone was statistically the same as ones of the group I bulbs germinated in distilled water medium while their micronucleus frequency and chromosomal aberrations excessively increased according to ones of 
the group I (Table 2). In this case, it may be said that some aberrations may result from this amino acid.

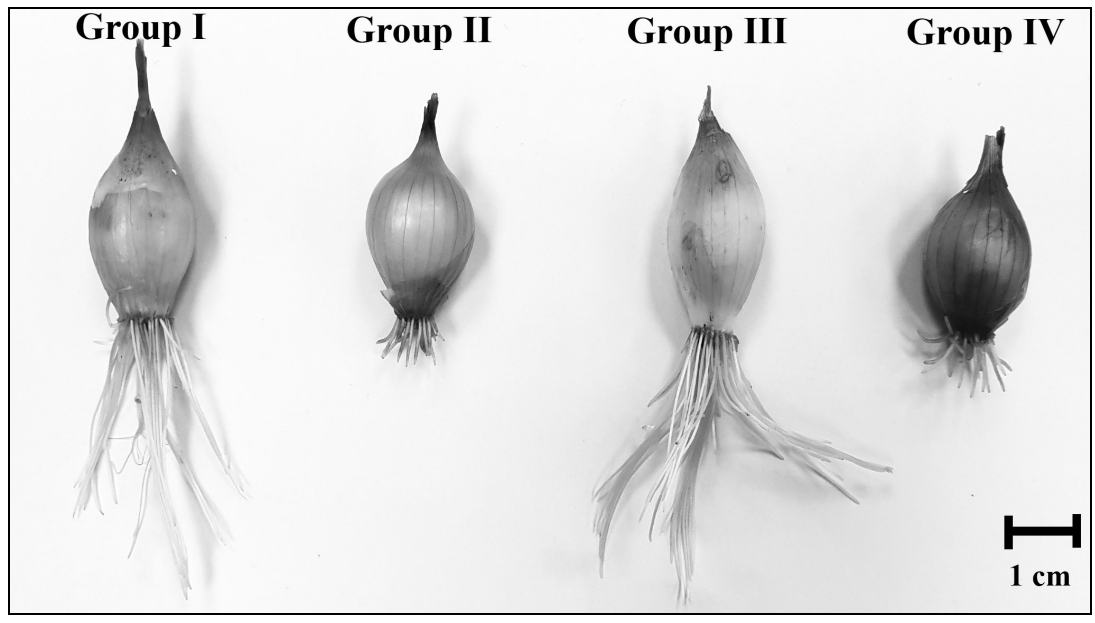

Fig. 1. The germination situations at the end of seventh day of Allium cepa bulbs. Group I was treated with distilled water, Group II was treated with $0.175 \mathrm{~m} \mathrm{NaCl}$ alone, Group III was treated with $150 \mathrm{mg} / \mathrm{l} \mathrm{dose}$ of L-ornithine and Group IV was treated with $150 \mathrm{mg} / \mathrm{l}$ dose of L-ornithine $+0.125 \mathrm{M} \mathrm{NaCl}$. Scale bar $=1 \mathrm{~cm}$.

Table 2. Effect of L-ornithine on some cytogenetical parameters of Allium cepa $\mathbf{L}$.

\begin{tabular}{lccc}
\hline Groups & $\begin{array}{c}\text { Mitotic index } \\
(\%)\end{array}$ & $\begin{array}{c}\text { Micronucleus frequency } \\
(\%)\end{array}$ & $\begin{array}{c}\text { Chromosome aberration } \\
(\%)\end{array}$ \\
\hline Group I & $* 15.9 \pm 0.4^{\mathrm{b}}$ & $0.3 \pm 0.5^{\mathrm{a}}$ & $0.8 \pm 0.0^{\mathrm{a}}$ \\
Group II & $5.5 \pm 0.4^{\mathrm{a}}$ & $18.3 \pm 0.5^{\mathrm{c}}$ & $60.8 \pm 0.4^{\mathrm{c}}$ \\
Group III & $15.9 \pm 0.5^{\mathrm{b}}$ & $7.3 \pm 0.5^{\mathrm{b}}$ & $52.6 \pm 1.3^{\mathrm{b}}$ \\
Group IV & $15.6 \pm 0.9^{\mathrm{b}}$ & $7.6 \pm 0.5^{\mathrm{b}}$ & $74.8 \pm 1.4^{\mathrm{d}}$ \\
\hline
\end{tabular}

*The difference between values with the same letter in each column is not significant at the level $0.05( \pm \mathrm{SD})$. Group I (control) treated with distilled water, Group II treated with $0.125 \mathrm{M} \mathrm{NaCl}$ alone, Group III treated with $150 \mathrm{mg} / \mathrm{l}$ dose of L-ornithine, Group IV treated with $150 \mathrm{mg} / \mathrm{l} \mathrm{dose}$ of L-ornithine+0.125 M NaCl.

The inhibitory and cytotoxic effects of salt stress on mitotic activity are known for a long time (Radic et al. 2005). High salt concentration causes total inhibition of mitotic activity, micronucleus frequency and chromosomal abnormalities in root-tip cells (Çavuşoğlu et al. 2017, 2018). In the present work, $0.125 \mathrm{M}$ salinity was found to decrease mitotic activity expressed as mitotic index according to ones of the control group and caused a significant increase on the micronucleus frequency and chromosomal aberrations. For instance, the mitotic index, micronucleus frequency and chromosomal aberrations in the root tip meristems of the bulbs germinated in normal conditions were 15.9, 0.3 and 0.8 , respectively while they were $5.5,18.3$ and 60.8 at $0.125 \mathrm{M} \mathrm{NaCl}$ medium. Besides, L-ornithine $+\mathrm{NaCl}$ application (Group IV) showed a perfectly good performance in ameliorating the negative effects of salt on the mitotic index (15.6) and micronucleus frequency (7.6). However, this application was ineffective in reducing the salt 
damage on the chromosome aberrations (74.8). All this values mentioned are substantially significant (Table 2).

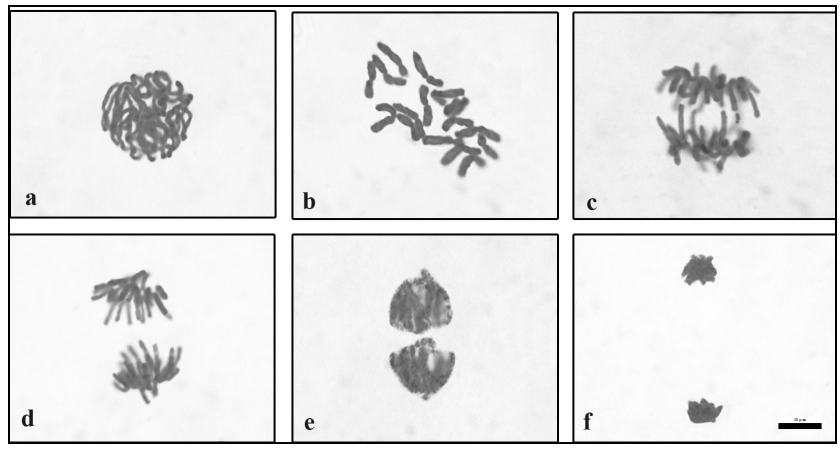

Fig. 2. Normal mitosis phases in root tip meristem cells of Allium cepa L. Prophase (a), metaphase (b), delayed anaphase (c), anaphase (d), early telophase (e), telophase (f). Scale bar $=10 \mu \mathrm{m}$

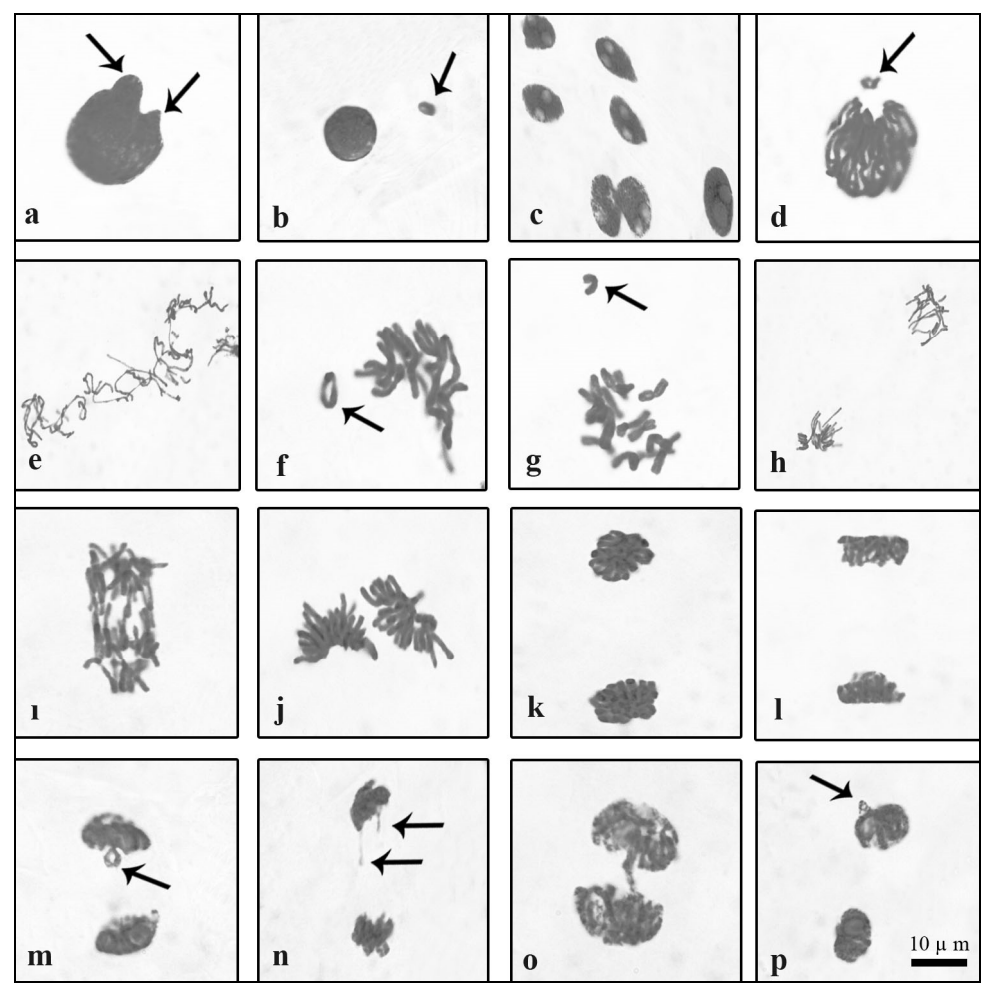

Fig. 3. Types of chromosomal aberration. Nucleus with nuclear buds $=$ arrows (a), micronucleus $=$ arrow (b), binucleolars (c), prophase with chromosome loss = arrow (d), irregular prophase (e), metaphase with ring chromosome = arrow (f), metaphase with chromosome loss $=$ arrow (g), abnormal anaphase (h), multiple bridge formation in anaphase (1), diagonal at anaphase (j), chained telophase (k), alignment telophase (1), telophase with chromosome loop = arrow $(\mathrm{m})$, lagging chromosomes $=$ arrows $(\mathrm{n})$, bridge formation in telophase $(\mathrm{o})$, diagonal at telophase with vagrant chromosome $=$ arrow $(\mathrm{p})$. Scale bar $=10 \mu \mathrm{m}$. 
Normal and abnormal mitotic phases observed during the microscopic examination of A. cepa root tip mitotic cells were indicated in Fig. 2 and Fig. 3. The most striking aberrations observed in all applications were micronucleus, irregular prophase, abnormal anaphase, nuclear buds, chromosome losses, bridge formation in anaphase/telophase, diagonal at anaphase/telophase with vagrant chromosome, metaphase with ring chromosome, chained telophase, lagging chromosomes, alignment telophase, telophase with chromosome loop. The majority of chromosomal aberrations in root tip cells treated with L-ornithine or salt were determined as binucleolars (Fig. 3).

Chromosomal abnormalities (CAs) are changes in chromosome structure resulting from a break or exchange of chromosomal material. Induction of CAs can affect the fertility, vigour, competitive or yield ability of the exposed plants (Kara et al. 1994). Nuclear buds arise as a result of excessive production of proteins and nucleic acids, induced by cytotoxicans (Fig. 3a) (Fenech et al. 2011). Micronucleus (Fig. 3b) is composed either of small chromatin fragments, which arise as a result of chromosomal breakage or of whole chromosomes that do not migrate anaphase as a result of spindle dysfunction. Chromosome losses (Fig. 3d, g) are alterations typically associated with the malfunction of the mitotic spindle. Abnormal anaphase (Fig. 3h) might be due to disturbance of spindle apparatus which allows that the chromosomes spread irregularly over the cell (Luzhna et al. 2013). Bridge formation (Fig. 31, o) resulted from chromosome and/or chromatid breaks, indicating the mutagenic event in the cell (Leme and Marin-Morales 2009). Lagging chromosomes (Fig. 3n) are the direct results of breaks and fragmentation, which lead to the loss of centromere and the stopping of their movement (Paul et al. 2013). İrregular prophase failure (Fig. 3e) can induce chromosome loss once they cannot bind to the spindle and therefore not segregate (Gisselsson et al. 2004). Ring chromosome (Fig. 3f) might arise due to the spontaneous breakage of chromosomal ends, followed by the joining of the raw ends of the chromosomes (Khanna and Sharma 2013). Diagonal orientation at anaphase/telophase (Fig. 3j, p) was due to a slight tilt in the spindle apparatus (Renjana et al. 2013).

There is no present literature data related to the effects of L-ornithine application in both normal and saline conditions on the physiological and cytogenetic parameters. Therefore, results of the present study have been reported for the first time in non-stress and salt stress conditions. Results showed that L-ornithine may significantly improve the activations such as the germination, seedling growth and mitotic activity in saline conditions. However, the mechanisms by which salinity inhibits growth are complex and controversial. Moreover, they might vary according to cultivar and species. An universal mechanism has not been established yet. Although the reasons of salinity have been characterized, understanding of the mechanisms by which salinity prevents plant growth is still very poor. Therefore, further works should be carried out in order to gain more knowledge about the effect of L-ornithine on cell division, cell cycle and molecular metabolism of germination. This literature study may serve to provide new conceptual tools for designing hypotheses of salt tolerance in plants.

\section{References}

Çavuşoğlu K, Cadıl S and Çavuşoğlu D 2017. Role of potassium nitrate $\left(\mathrm{KNO}_{3}\right)$ in alleviation of detrimental effects of salt stress on some physiological and cytogenetical parameters in Allium cepa L. Cytologia 82(3): 279-286.

Çavuşoğlu D, Çavuşoğlu K and Tabur S 2018. The effects of Black cumin (Nigella sativa L.) seed extract on the seed germination, seedling growth, mitotic activity and chromosomal abberations of Allium cepa $\mathrm{L}$. under saline condition. ARPN. 13(5): 50-57.

Demidchik V, Shabala S, Isayenkov S, Cuin TA and Pottosin I 2018. Calcium transport across plant membranes: mechanisms and functions. New Phytol. 220(1): 49-69. 
Fenech M, Kirsch-Volders M, Natarajan AT, Surralles J, Crott JW, Parry J, Norppa H, Eastmond DA, Tucker JD and Thomas P 2011. Molecular mechanisms of micronucleus, nucleoplasmic bridge and nuclear bud formation in mammalian and human cells review. Mutagenesis 26: 125-132.

Flowers TJ and Colmer TD 2015. Plant salt tolerance: adaptations in halophytes. Annals. Bot. 115(3): 327-331.

Gajalakshmi K and Ruban P 2014. Evaluation of physic chemical parameters and cytotoxic effect of Orathupalayam dam in Tirupur District. Int. J. Agric. Pol. Res. 2(5): 191-197.

Gisselsson D, Palsson E, Yu C, Mertens F, Mandahl N 2004. Mitotic instability associated with late genomic changes in bone and soft tissue tumours. Cancer Lett. 206: 69-76.

Kara M, Tanda MA and Ateş A 1994. Cytogenetic effects of the insecticide cypermethin on the root meristems of Allium cepa L. Tr. J. of Biol. 18: 323-331.

Khanna N and Sharma S 2013. Allium cepa root chromosomal aberration assay. Ind. J. Pharm. Biol. Res. 1(3): 105-119.

Leme DM and Marin-Morales MA 2009. Allium cepa test in environmental monitoring: a review on its application. Mutat. Res. 682: 71-81.

Luzhna L, Kathiria P and Kovalchuk O 2013. Micronuclei in genotoxicity assessment: from genetics to epigenetics and beyond. Front. Genet. 4: 131.

Mattoo AK and Handa AK 2008. Higher polyamines restore and enhance metabolic memory in ripening fruit. Plant Sci. 174: 386-93.

Paul A, Nag S and Sinha K 2013. Cytological effects of Blitox on root mitosis of Allium cepa L. Int. J. Sci. Res. Pub. 3(5): 2250-3153.

Radic S, Prolic M, Pavlica M and Pevalek-Kozlina B 2005. Cytogenetic effects of osmotic stress on the root meristem cells of Centaurea ragusina L. Env. Exp. Bot. 54: 213-218.

Renjana PK, Anjana S and Thoppil JE 2013. Evaluation of genotoxic effects of baking powder and monosodium glutamate (MSG) using Allium cepa assay. Int. J. Pharm. Sci. 5: 132-139.

Roy SJ, Negrão S and Tester M 2014. Salt resistant crop plants. Curr. Opin. Biotechnol. 26: 115-124.

Schneider J, Eberhardt D and Wendisch VF 2012. Improving putrescine production by Corynebacterium glutamicum by fine-tuning ornithine transcarbamoylase activity using a plasmid addiction system. Appl. Microbiol. Biotechnol. 95: 169-178.

Shrivastava P and Kumar R 2015. Soil salinity: A serious environmental issue and plant growth promoting bacteria as one of the tools for its alleviation. Saudi J. Biol. Sci. 22(2): 123-31. 